\title{
Effects of Ready-to-Eat Breakfast Cereals on Dental Caries Experience in Adolescent Children: A Three-Year Study
}

\author{
NATHANIEL H. ROWE, RAY H. ANDERSON, and LESTER A. WANNINGER \\ Dental Research Institute, Schools of Dentistry and Medicine, University of Michigan, \\ Ann Arbor, Michigan 48104, USA and Chemical Services and Nutrition, and Mathematics \\ and Operations Analysis, General Mills, Inc., Minneapolis, Minnesota
}

The 375 adolescent public school children who participated in a permissive three-year breakfast consumption study showed no differences in dental caries experience whether they ate ready-to-eat breakfast cereals or other dietary regimens.

The influence of dietary composition on dental caries experience has been well documented in experimental animals 1,2 and in man. ${ }^{3-5}$ Conflicting reports exist regarding the role of cereals in the genesis of, or protection against, dental caries. ${ }^{6-8}$ It would be helpful for dietary counseling of the adoles. cent child if information could be generated to determine whether consumption of modern ready-to-eat breakfast cereals should be avoided, ignored, or encouraged. While conducting a clinical trial on adolescent children to determine the effect of phosphate enrichment of ready-to-eat breakfast cereals on dental caries experience, we had an opportunity to analyze whether the incorporation of ready-to-eat cereal into the breakfast regimen altered dental caries experience from that of children who consumed other foods for breakfast.

\section{Materials and Methods}

Ann Arbor seventh grade public school children of both sexes were enrolled in a permissive dental caries prevention study by parental consent. Participants were provided at monthly intervals, ad libitum, toothbrushes, ${ }^{a}$ dentifrice, ${ }^{b}$ and seven varieties of

This study was sponsored by the University of Michigan, financially supported by General Mills, Inc., Minneapolis, Minn, and conducted in cooperation with the Ann Arbor Public Schools System.

Received for publication January 22, 1973 .

- Oral B30, Oral B Company, Wayne, NJ.

b Crest, Procter \& Gamble Co., Cincinnati, Ohio. ready-to-eat breakfast cereal delivered to their homes. Cereals were produced and packaged for the study by General Mills, Inc. (Minneapolis, Minn). Cereals were not identified for the participants. Cereals marketed under the names Wheaties, Cheerios, Corn Flakes, Trix, Cocoa Puffs, Frosty O's, and Corn Bursts were dispensed in plain white 7 ounce boxes labeled simply wheat flakes, corn cereal, oat cereal, fruit-flavored corn puffs, cocoa-flavored cereal, sugared oat cereal, and corn puffs (in addition to federally required information). The last four cereals were presweetened, whereas the first three were not.

Participants were instructed that adherence to a rigid schedule for eating the study cereals was not required. Parents were requested to have the study cereals available, but the participant was free to eat as much or as little of them as he desired. Some advised us that after a brief "novelty period," bacon and eggs, cooked cereal, and so on were preferred to the study cereals, and as a consequence the participant no longer ate the study cereal. Children were reminded that participation in the study did not require them to eat the study cereal in lieu of a preferred or customary breakfast regimen. This provided us with the opportunity to examine dental caries increments in ready-toeat breakfast cereal eaters vs those who ate other foods for breakfast.

Complete three-year data for 375 children were available for analysis at the conclusion of the study. These children of both sexes had been an average of 13 years of age (standard deviation, 0.38 ) at the beginning of the study period. Cereal was dispensed after an initial six-month delay (to comply with a United States Food and Drug Admin- 
istration directive). Dental caries experience was determined initially and annually thereafter.

Examinations were conducted by two experienced dentists. One conducted all the clinical examinations; the other conducted all the radiographic examinations at the 0-, 12-, 24-, and 36-month intervals. Participants were instructed individually in oral hygiene by a hygienist; instruction was followed by supervised brushing. The participant was seated in a head-rest-equipped portable dental chair and teeth were examined with a mirror and explorer. High intensity light was carried uniformly to each of the participant's teeth by a fiber optic light catheter within a hollow-handled mouth mirror. Verbalized observations were recorded (by another dentist). Seven radiographs (bitewing and anterior) were taken per individual per year.

Careful records were maintained by one person throughout the study period; the amount and type of cereal supplied to each participant were listed. Of the cereals requested, $60 \%$ were presweetened (sugarcoated). For the purpose of this analysis, a participant was assigned to the "noncereal eater" group if he consumed less than 28 boxes during the three-year study period. This amounted to less than one box per month, which was, at the most, less than one serving every fourth day. This is an arbitrary categorization, the effect of which was checked statistically by reassignment on the basis of 50 boxes per child. Results were similar; thus, assignment error is probably negligible. Considerable variation in the amount of cereal requested by the various participants was observed as expected (Table 1).

\section{Results}

Only three-year data (30-month cereal use) are analyzed here. This was done to discriminate against (1) the novelty effect (which probably did occur in the early months), that is, sampling the test cereals and then quickly reverting to previous dietary regimens with the uneaten portion discarded, and (2) questionable examiner judgment in the case of incipient lesions, which are known to plague short-term dental caries studies. ${ }^{9}$

Similarity of the two groups with respect to age, sex, and previous and incremental
TABLE I

Frequency Distribution of Participants According to the Total Number of Boxes of Cereal Supplied During The Three-Year STUDY PERIOD

\begin{tabular}{ccc}
\hline \hline Boxes & $\begin{array}{c}\text { No. of } \\
\text { Participants }\end{array}$ & Percent \\
\hline $0-20$ & 51 & 8.5 \\
$20-40$ & 48 & 13.6 \\
$40-60$ & 46 & 13.0 \\
$60-80$ & 33 & 9.3 \\
$80-100$ & 25 & 7.1 \\
$100-120$ & 21 & 5.9 \\
$120-140$ & 21 & 5.9 \\
$140-160$ & 13 & 3.7 \\
$160-180$ & 5 & 1.4 \\
$180-200$ & 13 & 3.7 \\
$200-220$ & 15 & 4.2 \\
$220-240$ & 15 & 4.2 \\
$240-260$ & 7 & 2.0 \\
$260-280$ & 6 & 1.7 \\
$280-300$ & 8 & 2.3 \\
$300-320$ & 3 & .8 \\
$320-340$ & 4 & 1.1 \\
$340-360$ & 5 & 1.4 \\
$360-380$ & 7 & 2.0 \\
$380-400$ & 6 & 1.7 \\
$400-500$ & 16 & 4.5 \\
$500-600$ & 6 & 1.7 \\
$600-700$ & 1 & 0.3 \\
\hline
\end{tabular}

dental caries experience is evident (Table 2). When the null hypothesis (no difference exists between those who ate the study cereal and those who did not) was applied, rejection was not accomplished. Statistical analysis of the incremental dental caries data by stepwise multiple regression and analysis of variance including age, sex, and initial caries experience plus eaters-noneaters as factors, also showed no difference between cereal eaters and noneaters.

In view of the great variation in the number of boxes of cereal supplied to the participants during the course of the study, an additional analysis was made in which those who received more than 200 boxes ("heavy eaters") were compared with the noneaters. Data revealed no difference in caries increments between the heavy eaters and the noneaters.

\section{Discussion}

Positive and negative group assignment errors are possible. The participant could have eaten other ready-to-eat breakfast cereals as a substitute for the study cereal; 
TABLE 2

Comparative dental Caries Experience of Adolescent Public School Children Who ate Ready-to-Eat Breakfast Cereals and Those Who Did Not

\begin{tabular}{|c|c|c|c|c|c|c|c|}
\hline & \multicolumn{2}{|c|}{ Mean } & \multicolumn{2}{|c|}{ Standard Deviation } & \multirow[b]{2}{*}{ Difference } & \multirow[b]{2}{*}{ Percent } & \multirow[b]{2}{*}{$t$} \\
\hline & $\begin{array}{l}\text { Eaters } \\
\text { (302) }\end{array}$ & $\begin{array}{c}\text { Noneaters } \\
(73)\end{array}$ & Eaters & Noneaters & & & \\
\hline Age (in years) & 13.10 & 13.05 & 0.37 & 0.40 & 0.05 & 0.4 & 0.98 \\
\hline Sex & $0.53 *$ & $0.45^{*}$ & 0.50 & 0.50 & 0.08 & 15.4 & 1.24 \\
\hline Initial DMF teeth & 4.55 & 5.11 & 2.92 & 3.27 & -0.56 & -12.3 & -1.34 \\
\hline Initial DMF surfaces & 6.12 & 7.25 & 4.41 & 5.67 & -1.12 & -18.3 & -1.58 \\
\hline Incremental DMF teeth & 3.24 & 3.63 & 2.69 & 2.90 & -0.39 & -11.9 & -1.04 \\
\hline Incremental DMF surfaces & 5.20 & 6.41 & 4.67 & 5.62 & -1.21 & -23.2 & -1.70 \\
\hline
\end{tabular}

* Male $=1 ;$ female $=0$.

thus, from shipping records he would have been recorded as a noncereal eater. Because of the economics of the situation (the study cereal was free and ordered by the parent), it is unlikely that this situation occurred. Interviews by telephone with parents at various times during the study, as well as direct interviews with each participant at the three annual examinations, strongly reinforced this belief.

The opposite error of the participant's family consuming the cereal, while the subject himself ate alternate foods, also was possible. Telephone interviews with parents would be less likely to reveal this source of error because of fear that the free cereal supply would cease if the situation were discovered. Again, the rules encouraged frankness. It had been stated at the outset that supplies would be provided to each participant for the duration of the study regardless of consumption. Even so, a small amount of this type of error probably did occur. Good rapport with the participants who were interrogated annually and the candidness of children at this age (especially when they knew that judgment was not made whether they responded affirmatively or negatively with regard to preference of cereal variety, or whether they ate it or not) leads us to believe that the magnitude of this error was small.

Although absolute homogeneity of either sample cannot be completely assured, the practical question of dietary counseling with regard to incorporation or avoidance of ready-to-eat breakfast cereals can be approached in general terms. In the present study, in which conditions more or less ap- proximated those of the average American adolescent child, factors other than incorporation or avoidance of ready-to-eat breakfast cereals completely dominated dental caries causal relationships. Under conditions of water fluoridation (the Ann Arbor municipal water supply has contained $1.1 \mathrm{ppm}$ fluoride since 1952) and oral health enlightenment (dental care and consciousness enjoy a relatively high level in this community), recognizable benefit or harm from consumption of ready-to-eat breakfast cereals in place of other breakfast regimens could not be identified.

\section{Conclusions}

Under the conditions of this study, adolescent children who consumed ready-to-eat breakfast cereals did not differ with respect to dental caries activity from classmates who consumed other breakfast dietary regimens.

We thank P. Carrigan, director, and C. Towers of the Ann Arbor Public Schools System, Department of Research, for assistance in coordinating the clinical phase of this study with the pupils, teachers, and administrators involved. Examiners during the field study were J. A. Regezi, USAF, Travis Air Force Base, California, and J. P. Sapp, Department of Pathology, The University of Western Ontario, London, Canada. We acknowledge the interest and cooperation of the principals, teachers, and participants and their parents.

\section{References}

1. KöNIG, K.G.: Feeding Regimens and Caries, $J$ Dent Res 49: 1327-1332, 1970.

2. Krasse, B.: The Effect of the Diet on the Implantation of Caries-Inducing Streptococci in Hamsters, Arch Oral Biol 10: 215-221, 1965

3. JAy, P.: The Reduction of Oral LactobacilIus Acidophilus Counts by the Periodic Restriction of Carbohydrate, $A m$ J Orthod 33: 162-184, 1947. 
4. Mandel, I.D.: Effects of Dietary Modifications on Caries in Humans, $J$ Dent Res 49: $1201-1211,1970$.

5. Nikiforuk, G.: Posteruptive Effects of Nutrition on Teeth, $J$ Dent Res 49: 1252-1261, 1970.

6. Hoppert, C.A.; Webrer, P.A.; and Canniff, T.L.: The Production of Dental Caries in Rats Fed an Adequate Diet, Science 74: 77-78, 1931.

7. KLeIN, H., and MCCollum, E.V.: A Preliminary Note on the Significance of the Phos- phorus Intake in the Diet and Blood Phosphorus Concentration in the Experimental Production of Caries-Immunity and CariesSusceptibility in the Rat, Science 74:662664,1931 .

8. OsBorN, T.W.B., and Noriskin, J.N.: The Relation Between Diet and Caries in the South African Bantu, J Dent Res 16: 431-441, 1937.

9. DE Paola, P.F.: Examiner Inconsistency in Clinical Caries Research, J Oral Ther 4: 200204, 1968. 